\title{
O OPEN ACCESS \\ Doppler ultrasound and tibial tuberosity maturation status predicts pain in adolescent male athletes with Osgood-Schlatter's disease: a case series with comparison group and clinical interpretation
}

\author{
Matthieu Sailly, ${ }^{1}$ Rod Whiteley, ${ }^{2-, 4}$ Amanda Johnson ${ }^{5,6}$
}

\begin{abstract}
${ }^{1}$ Centre de Biologie et de Medecine du Sport de Pau, Centre Hospitalier Pau, Pau, France

${ }^{2}$ Aspetar Orthopaedic and Sports Medicine Hospital, Doha, Qatar

${ }^{3}$ University of Sydney, Sydney, Australia

${ }^{4}$ University of New England, Armidale, Australia

${ }^{5}$ Aspire Academy for Excellence-NSMP, Doha, Qatar

${ }^{6}$ University of Manchester, Manchester, UK
\end{abstract}

\section{Correspondence to} Dr Matthieu Sailly, Centre de Biologie et de Medecine du Sport de Pau, Centre Hospitalier Pau, Pau, France; matthieusailly@yahoo.fr

Accepted 12 August 2012 Published Online First 5 September 2012
To cite: Sailly $M$, Whiteley R, Johnson A. Br J Sports Med 2013, 47, 93-97.

\begin{abstract}
Background The pathogenesis of the OsgoodSchlatter's disease (OSD) is still debated. The fragmentation of the ossification centre has been questioned as a definitive sign of OSD and has been seen as a normal development of the anterior tibial tubercle (ATT).

Objectives It is unknown if such changes are present in the presumed pathological tendon insertion seen in OSD, nor the relation of Doppler-positive changes to pain on clinical examination.
\end{abstract}

Methods A prospective analysis was carried out on 20 consecutive symptomatic male athletes (13.9 years \pm 1.3 ) and a comparison group of asymptomatic subjects. All underwent a comparative clinical assessment and ultrasound with colour Doppler scan on both knees. Subjective pain was recorded with a visual analogue scale (VAS) during provocative manoeuvres: palpation, resisted contraction and single leg squat.

Results Positive Doppler US (within the distal end of the patellar tendon) was associated with higher pain on palpation $(47 \pm 24.5$ vs $18 \pm 11.4, p<0.01)$ and resisted static contraction $(59 \pm 20.2$ vs $27 \pm 12.5, p<0.001)$ compared with Doppler-negative subjects. No Doppler activity was found in the comparison group. VAS for palpation and resisted contraction of the athletes graded as stage $2(51.1 \pm 22.0$ and $60.0 \pm 21.2)$ were significantly higher than stage $3(17.8 \pm 12.0$ and 18.9 $\pm 16.9)$ and stage $4(15.0 \pm 7.1$ and $25.0 \pm 7.1 ; p<0.01)$. Conclusions More painful OSD is associated with the presence of neo-vessels. This may be linked with a particular stage of ATT maturation and applied compressive forces. A Doppler ultrasound scan adds practical information to develop the care plan of the patient.

\section{INTRODUCTION}

Osgood-Schlatter's disease (OSD) was first described in the early $1900 \mathrm{~s}^{12}$ and is now classified as an apophysitis of the anterior aspect of the tibial tuberosity (ATT). It is a common condition in an active youth population ${ }^{3} 4$ and is said to be responsible for a significant number of days lost from training and competition. ${ }^{5}$ OSD occurs during the early adolescent period which is a critical phase of any long-term athlete development plan, and therefore such a condition which incurs significant time loss from training and competition can adversely affect the ultimate performance level.

The pathogenesis of this growth-related condition is still debated. The diagnosis is essentially clinical but radiology is often used for confirmation. Based on x-ray, ${ }^{6}$ ultrasound ${ }^{7-10}$ and $\mathrm{MRI}^{11}$ investigations, different aetiologies have been developed. The initial hypothesis described the repetitive traction of the patellar tendon on the distal insertion as the main area of secondary ossification centre fragmentation and transitory necrosis. ${ }^{412} 13$ This fragmentation has been questioned as a definitive sign of OSD and has subsequently been seen as a normal development of the ATT. ${ }^{14}$ Fragmentation of the ATT is found in symptomatic as well as asymptomatic knees and therefore cannot be used to discriminate between the normal and abnormal pathology. ${ }^{14-17}$ Subsequent to these studies, Ducher et $a l^{14}$ developed a maturation staging of the ATT using ultrasonography. Three developmental stages are described, principally in asymptomatic subjects. In Ducher's classification, stage 1 is delineated as a cartilage attachment, initially without, and subsequently with ossicles. Stage 2 demonstrates insertional cartilage, and stage 3 is a mature attachment. ${ }^{14}{ }^{18}$ Relatively recently, it has been suggested that the presence of neo-vessels in and/or around a symptomatic tendon, as demonstrated by a Doppler-positive ultrasound, could be a hallmark feature of a pathological tendon. It is unknown if such changes are present in the presumed pathological tendon insertion seen in OSD, nor the relation of Doppler-positive changes to pain on clinical examination.

It is proposed that examining both symptomatic and asymptomatic knees of OSD sufferers to ascertain the maturation status, as described by Ducher et al ${ }^{14}$ and the presence of neo-vessels as indicated by Doppler ultrasound could shed light on the pathogenesis and provide clinical insight into the management of this troubling and common condition.

\section{METHODOLOGY \\ Cohort}

A prospective analysis was carried out from April 2010 until May 2011 on a consecutive series of 20 symptomatic adolescent male students who were all attending a Middle Eastern Sports Academy. The group consisted of 17 soccer players, two squash players and one middle distance athlete (mean age 13.8 years (SD 1.37), range 12.2-16.3). Both knees were assessed for all athletes and comparison was made between the two limbs. In total, 15 athletes complained of unilateral symptoms and seven bilateral symptoms (two recurrences). Of the original group of 20 athletes, five had at least one reassessment due to a recurrence of symptoms after initial discharge from care. A comparison group of 68 
asymptomatic knees in 35 athletic adolescent men attending the same Academy were scanned (12.4 years (2.65), 9.5-17.1) and independently rated and clinically assessed in the same manner as the clinical group.

The inclusion criterion to be part of the OSD group was the inability to continue their physical activities due to anterior knee pain. History of onset could be either progressive or acute following a direct trauma on the ATT. Pain had to be localised at the ATT site that increased by palpation, and resisted isometric knee extension. ${ }^{6}$ Criteria of exclusion were knee effusion, patella instability, femoro-patellar syndrome and Sinding Larsen disease.

Consent for investigation was given by the parents or guardians, and the study was conducted in accordance with the declaration of Helsinki.

\section{Clinical investigation}

All athletes were clinically assessed using the same subjective and objective criteria. Subjective criteria included a history of any anterior knee pain inferior to the patella. Subjects were asked regarding daily and sporting activity which provoked this particular pain, as well as their estimate of the level of this pain on a $0-100$ point visual analogue pain scale (VAS) with 0 signifying no pain and discomfort and 100 extreme pain and discomfort.

During the standardised physical examination, palpation of the tibial tuberosity was carried out and discomfort levels measured using a VAS. A resisted contraction of the extensor mechanism was carried out in a prone position with the knee at $90^{\circ}$ of flexion with the subject reporting the VAS. A single leg squat with arms folded across the chest was carried out as a functional test with the VAS recorded. All physical examination was conducted by the same experienced medical practitioner.

\section{Ultrasound imaging}

All athletes underwent an ultrasound scan by the same experienced practitioner, using a linear probe $12-7 \mathrm{MHz}$ (Siemens, Acuson 500, Erlangen, Germany). Longitudinal views of the distal insertion of the patellar tendon were recorded on a $90^{\circ}$ flexed knee.

The stages of maturation of the tibial tuberosity were based on the three-point scale initially based on the work by Grechenig et $a l^{19}$ and then further developed by Ducher et al. ${ }^{14}{ }^{18}$ In order to improve the accuracy of the developmental aspect of the apophysis, the choice was made to split the first stage into two. A fourstage classification was therefore used with stage 1 described as: cartilage attachment without ossicle; stage 2: cartilage attachment with ossicle; stage 3: insertional cartilage and stage 4: mature attachment. For a depiction of this classification system (see figure 1).

Colour-enhanced Doppler examination was performed on a fully extended knee with minimal sound head pressure to avoid compression of any neo-vessels. Doppler sensitivity was $5.7 \mathrm{~cm} / \mathrm{sec}$. Doppler activity and any ultrasound signs of bursitis were recorded as positive or negative as the case may be. Examples of Dopplerpositive OSD patients can be seen in figure 2 .

\section{Statistical analysis}

Descriptive and inferential statistical analysis was carried out using the statistical package SPSS for Windows (V.19.0, IBM, Chicago, Illinois, USA).

\section{RESULTS}

\section{OSD group}

Palpation scores measured 32.5 \pm 23.8 (range 0-90). Pain during resisted contraction was 38.0 27.1 (range 0-90). Pain during the single leg squat was $21.5 \pm 16.6$ (range $0-60$ ). Ten of the 20 athletes demonstrated a positive Doppler US of their ATT. In those subjects with a positive Doppler US, the pain during palpation $(47.0 \pm 24.5$ vs $18.0 \pm 11.4, \mathrm{p}<0.01)$ and resisted static contraction $(59.0 \pm 20.2$ vs $17.0 \pm 12.5, \mathrm{p}<0.001)$ was significantly higher than those boys in whom the Doppler was negative when examined using Student $t$ tests. During the single leg squat, there were no significant differences in VAS $(27.0 \pm 17.0$ for Doppler-positive vs $16.0 \pm 15.1, \mathrm{p}=0.144)$. See figure 3 for a depiction of these results.

Nine of the $10(90 \%)$ positive Doppler tests were stage 2 maturation for the ATTwhile the other athlete was stage 3. Of the 10 subjects who were Doppler-negative on initial examination, one was stage 2, seven were stage 3 and two were stage 4 . Examples of the US images of Doppler-positive subjects are shown in figure 2.

Examination of the maturation status of the ATT revealed a reduction in reported pain during both palpation and resisted static contraction with advancing skeletal maturation. The initial palpation on the 10 symptomatic subjects who were classified as stage 2 demonstrated an average VAS of $47.0( \pm 24.5)$, whereas the eight subjects classified as stage 3 reported a VAS of $18.8( \pm 12.5)$ and the two subjects classified as stage 4 had an average VAS of 15.0 ( \pm 7.1 ; see figure 4). Similarly, during resisted static contraction, those athletes classified as stage 2 had a higher VAS (57.0 $\pm 22.1)$ than those classified as stage $3(17.5 \pm 17.5)$. The two boys classified as stage 4 had an average VAS of $25.0( \pm 7.1)$ (figure 5).

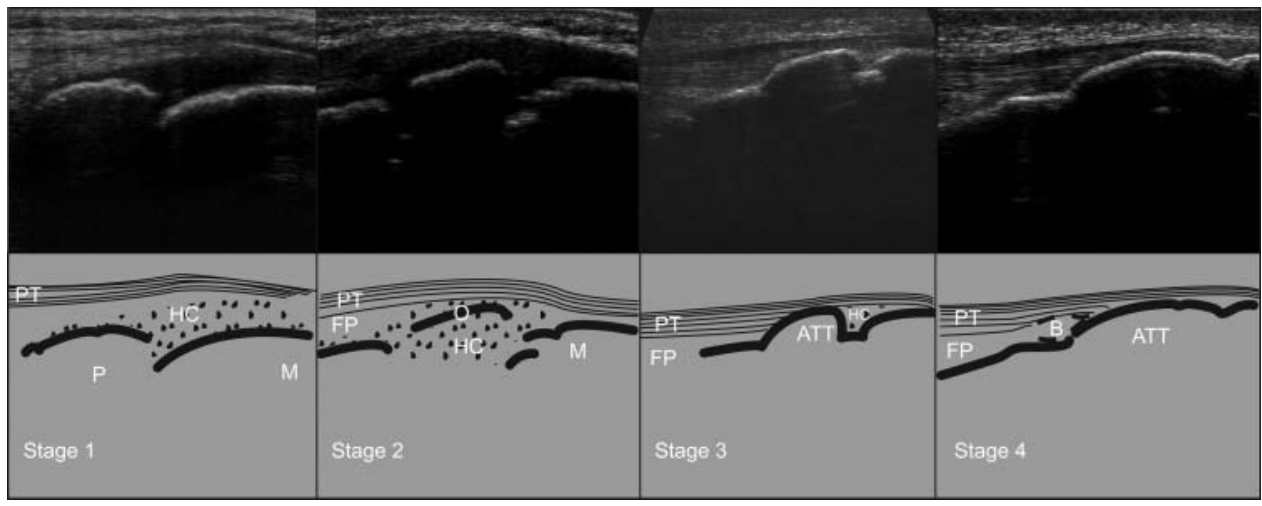

Figure 1 Classification system of the maturation status of the ATT from stages 1 to 4 . ATT, anterior tibial tuberosity; B, bursa; FP, fat pad; HC, hyaline cartilage; $\mathrm{M}$, metaphysic; $\mathrm{O}$, ossicle; $\mathrm{P}$, physis; $\mathrm{PT}$, patellar. 


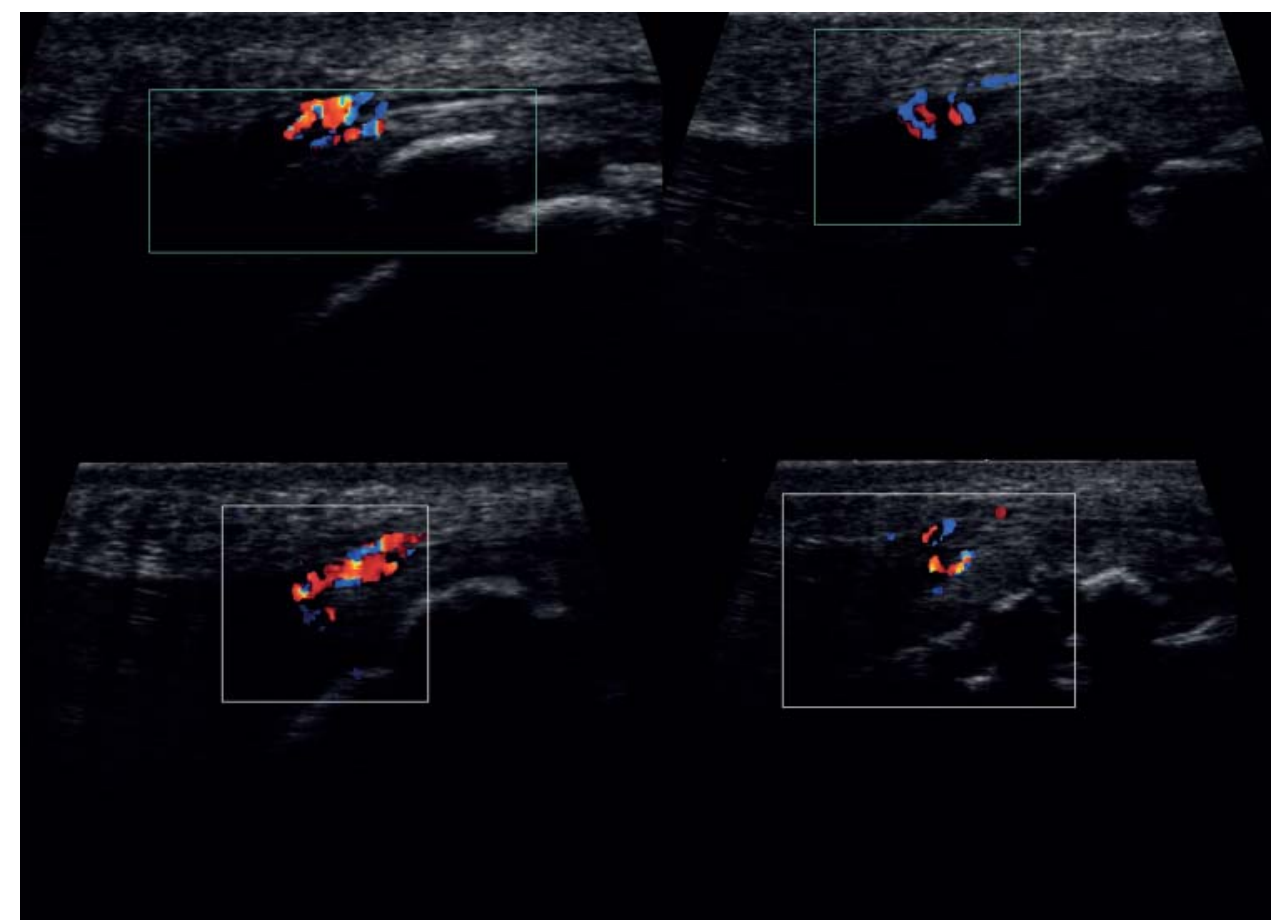

Figure 2 Representative images of Doppler-positive subjects in the painful cohort.

Seven of the athletes who complained of unilateral symptoms had reached stage 2 in the non-symptomatic limb; the others were either stage 3 or 4 . There was no evidence of Doppler in any of these asymptomatic limbs.

\section{Asymptomatic comparison group}

Of these 68 knees, there were 35 classified as maturation stage 1, 8 classified as stage 2, 9 classified as stage 3 and 16 classified as stage 4.There were no Doppler-positive findings in any of the tendons of the asymptomatic knees. There were occasional (6/68 knees) findings of vessels within the metaphysis. Thirty of the 33 asymptomatic boys who had both knees scanned were classified as having knees of the same maturation stage. The three boys with side-to-side differences were a maximum of one classification stage apart.

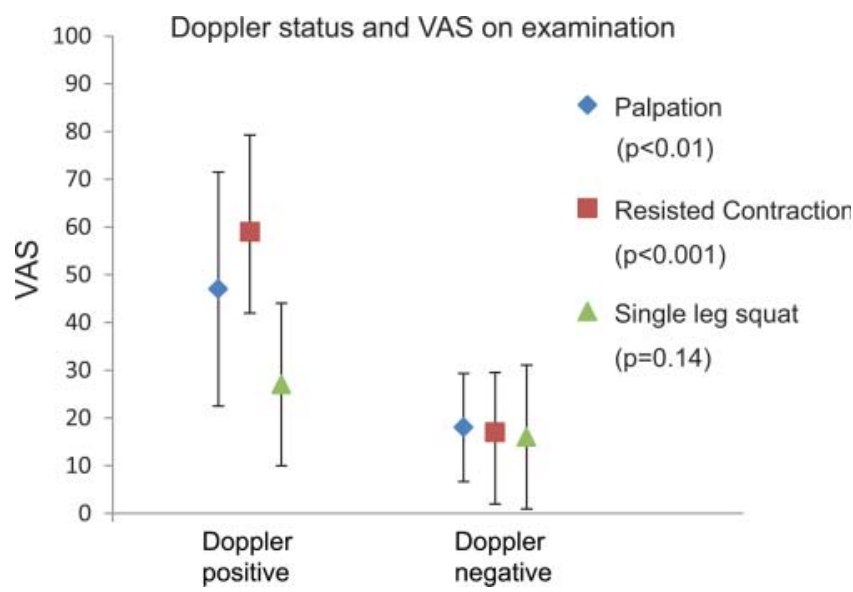

Figure 3 Reported visual analogue scale (VAS) for the three physical examination manoeuvres in the Osgood-Schlatter's disease (OSD) subjects according to Doppler US status.

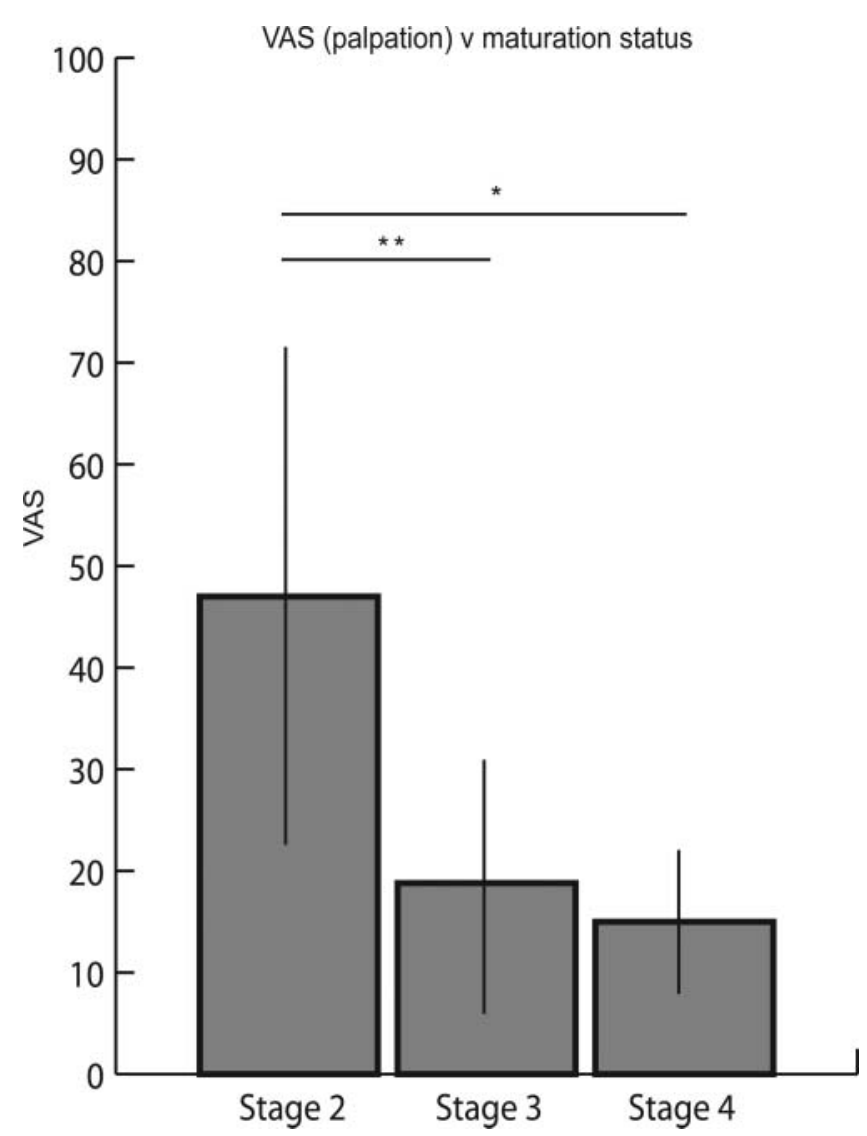

Figure 4 Visual analogue scale (VAS) for palpation during initial examination compared with maturation status. VAS for palpation of the athletes graded as stage $2(47.0 \pm 24.5)$ was significantly higher than stage $3(18.8 \pm 12.5, p<0.01)$ and stage $4(15.0 \pm 7.1 ; p=0.01)$, whereas there was no difference when comparing athletes classified as stages 3 and $4(p=0.61)$. 


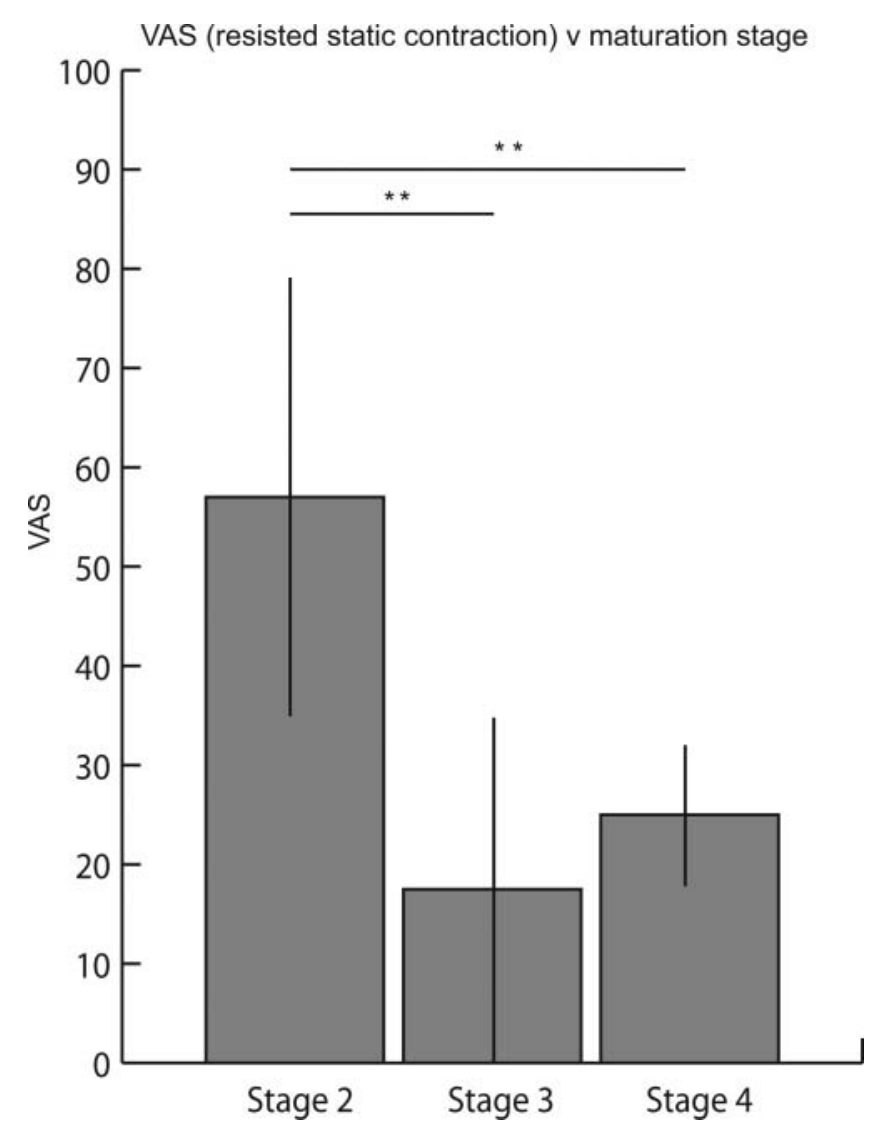

Figure 5 Visual analogue scale (VAS) for resisted static contraction during initial examination compared with maturation status. VAS for resisted static contraction of the athletes graded as stage $2(57.0 \pm 22.1)$ was significantly higher than stage $3(17.5 \pm 17.5)$ and stage 4 (25.0 $\pm 7.1 ; p<0.01)$, whereas there was no difference between those athletes classified as stages 3 and $4(p=0.39)$.

\section{DISCUSSION}

The modified version of Ducher's classification was a valid, effective and uncomplicated method to assess symptomatic and asymptomatic ATT. All ATT scanned with ultrasound were classified easily using this new staging scale. In addition, a routine Doppler scan added some clinically relevant findings which have altered our management algorithm for symptomatic OSD subjects.

To our knowledge, this is the first paper to document an association between Doppler US findings and pain on examination in OSD. This present series demonstrated that pain reported in symptomatic ATT with a Doppler activity was significantly higher than when no Doppler activity was found. Interestingly, no such relation was seen during the commonly performed physical examination manoeuvre of a single leg squat, which showed lower reported VAS. In a comparison cohort of painfree subjects (with similar activity levels) there were no findings of Doppler activity within the tendon.

Doppler activity has been reported to reflect the propagation of neo-vessels. ${ }^{20}$ Development of neo-vessels within the tendon has been shown to be associated with proliferation of nerve fibres that could be responsible for pain generation. ${ }^{21-23}$ In this study it was seen that the neo-vascularisation started from the prepatellar bursa and extended into the distal end of the patellar tendon; only a few cases showed vessel invasion from the deep infrapatellar bursa. Previous authors have suggested bony fragmentation as causative of pain in the secondary ossification centres. ${ }^{4} 1213$
Doppler activity was predominantly demonstrated in symptomatic subjects at stage 2 . This finding may be a pathognomonic sign of OSD as in this cohort subjects did not show any colour Doppler activity in the contro-lateral asymptomatic tendon. Further, there was no Doppler activity within the asymptomatic comparison group. For these reasons, the asymptomatic ATT maturation may be differentiated from the symptomatic knee through the use of Doppler examination for the presence of neo-vessels.

This study has demonstrated significantly lower levels of pain in subjects with later (stages 3 and 4) maturation of their ATT. The magnitude of the VAS difference demonstrated here is considered to be clinically meaningful as it exceeds a $33 \%$ change. $^{24} 25$ We suggest that documentation of the maturation status is clinically useful in determining the levels of pain likely encountered in symptomatic OSD.

In this series no subject reported symptoms of OSD at stage 1 . It is unknown as to whether symptoms can arise with this maturation stage; however, we speculate that stage 2 could be the critical stage of development where the likelihood of symptomatic OSD is heightened. We suggest that the described modification of Ducher et al's ${ }^{14}$ staging system is warranted as this cohort has shown no painful subjects in stage 1 , and a majority in stage 2 . In Ducher et al's ${ }^{14}$ classification system, all of these subjects would have been classified as stage 1 .

The development and the maturation of the enthesis is a subject of on-going investigation. ${ }^{8}$ Gao et $a l^{26}$ have highlighted the structural similarities between growth plate and the enthesis. MRI investigations of immature ATT described the close relation between the tibial physis and the apophyseal cartilage. Structural similarities and close anatomical localisation invite comparison between the maturation of the enthesis fibrocartilage cells with the maturation of the epiphysial growth plate. ${ }^{8} 27$ In this light, Benjamin et $a l^{28}$ advocated that the enthesis maturation may follow a similar pattern: initial hyperplasia of the chondrocyte within the hyaline apophyseal cartilage which may progress into cell apoptosis and a vascular invasion. This angiogenesis is regulated by different factors including vascular endothelial growth factor (VEGF) and several cartilage promoting growth factors (FGFa, FGFb, TGFb and IGF1) and is completed by a progressive osteogenesis. ${ }^{29} 30$ Anatomic studies have shown that these neo-vessels arising from the tibial metaphysis can be visualised with ultrasound during the ossification phase of the hyaline apophyseal cartilage (stages 2 and 3). ${ }^{14}$ These stages of maturation have been shown to be regulated by VEGF that promotes the neo-vessels invasion. VEGF is modulated by hypertrophic chondrocytes ${ }^{31} 32$ and resultant from compressive load. ${ }^{33}$ In this present series, all symptomatic subjects in stage 2 maturation showed a Doppler activity within the tendon. In the majority of cases these neo-vessels arose from the prepatellar bursa, although two appeared to arise from the deep infrapatellar bursa. In 2007 McGonagle et al, ${ }^{34}$ first described how the highly vascular synovium surrounding the enthesis formed bursae which were prone to inflammation. This inflammation of the bursae, seen in all symptomatic stage 2 subjects in the present investigation may be due to the over production of VGEF due to compressive forces. We speculate that there may be higher compressive forces and the pathological insertion seen during direct palpation and resisted static contraction in comparison to a single leg squat and this may help explain the higher reports of pain in these examination manoeuvres (figure 3).

In adolescents, the patellar ligament has been shown to attach not only on the developing tibial tubercle but also to broaden 
out to its attachment beyond the adjacent perichondrium of the physis and the periosteum of the adjacent metaphysic. ${ }^{35} 36$ This anatomical attachment may result in the ATT being submitted to either traction, but mainly compressive forces. Compression can be either a chronic micro repetitive load or a unique traumatic event such as a fall on the knee-a common history described by symptomatic subjects. ${ }^{37}$

This hypothesis may also help explain the success of complete rest (knee joint immobilisation) in the treatment of OSD. ${ }^{6} 3839$ The decrease of compression load may reduce the VEGF production and could prevent the neo-vessel invasion of the tendon. We suggest that clinically this may infer stage 2 cases require complete rest whereas stages 3 and 4 can be managed with training load modification only.

This series has shown that Doppler ultrasound scan and clinical examination could be helpful for the practitioner in the management and diagnosis of OSD.

\section{What this study adds}

- The addition of colour Doppler to US maturation staging may help to understand the pathogenesis of the Osgood-Schlatter's disease (OSD).

- Some stages of the anterior tibial tubercle maturation seem to be more vulnerable to the development of severe OSD.

- More painful OSD is associated with neo-vessel invasion within the end of the patellar tendon and this may be linked with compressive forces.

- An ultrasound scan may add some practical information to help develop the care plan of the patient.

Acknowledgements We are grateful to the Academy students and their parents for allowing this study, and the physiotherapy department for their on-going support.

Contributors MS was involved in original study design, data collection, data analysis, manuscript preparation. RW and AJ were involved in data analysis, manuscript preparation. All authors have reviewed and approved the final submission.

\section{Competing interests None.}

Ethics approval Aspetar hospital ethical committee approval.

Patient consent Obtained.

Provenance and peer review Not commissioned; externally peer reviewed.

Open Access This is an Open Access article distributed in accordance with the Creative Commons Attribution Non Commercial (CC BY-NC 3.0) license, which permits others to distribute, remix, adapt, build upon this work non-commercially, and license their derivative works on different terms, provided the original work is properly cited and the use is non-commercial. See: http://creativecommons.org/ licenses/by-nc/3.0/

\section{REFERENCES}

1 Osgood RB. Lesions of the tibial tubercle occurring during adolescence. Boston Med Surg J 1903;1:114-17.

2 Schlatter C. Verletzungen des schnabelformigen Fortsatzes der oberen Tibiaepiphyse. Beitr Klin Chir 1903;38:874-87.

3 Caine D, DiFiori J, Maffulli N. Physeal injuries in children's and youth sports: reasons for concern? Br J Sports Med 2006;40:749-60.

4 De Lucena GL, Dos Santos Gomes C, Guerra RO. Prevalence and associated factors of Osgood-Schlatter syndrome in a population-based sample of Brazilian adolescents. Am J Sports Med 2011 39:415-20.

5 Ross MD, Villard D. Disability levels of college-aged men with a history of Osgood-Schlatter disease. J Strength Cond Res 2003;17:659-63.

6 Gholve PA, Scher DM, Khakharia S, et al. Osgood Schlatter syndrome. Curr Opin Pediatr 2007;19:44-50.
7 Flaviis L, Nessi R, Scaglione P, et al. Ultrasonic diagnosis of Osgood-Schlatter and Sinding-Larsen-Johansson diseases of the knee. Skeletal Radiol 1989;18:193-7.

8 Blankstein A, Cohen I, Heim M, et al. Ultrasonography as a diagnostic modality in Osgood-Schlatter disease. A clinical study and review of the literature. Arch Orthop Trauma Surg 2001:121:536-9.

9 Czyrny ZGA. Osgood-Schlatter disease: a new perspective and classification based on ultrasonography. Ultrasonografia 2009;55-70.

10 Laine HR, Harjula A, Peltokallio P. Ultrasound in the evaluation of the knee and patellar regions. J Ultrasound Med 1987;6:33-6.

11 Demirag B, Ozturk C, Yazici Z, et al. The pathophysiology of Osgood-Schlatte disease: a magnetic resonance investigation. J Pediatr Orthop B 2004;13:379-82.

12 Kujala UM, Kvist M, Heinonen 0. Osgood-Schlatter's disease in adolescent athletes. Retrospective study of incidence and duration. Am J Sports Med 1985;13:236-41.

13 Katz JF. Nonarticular osteochondroses. Clin Orthop Relat Res 1981;158:70.

14 Ducher G, Cook J, Lammers G, et al. The ultrasound appearance of the patellar tendon attachment to the tibia in young athletes is conditional on gender and pubertal stage. J Sci Med Sport 2010;13:20-3.

15 Rosenberg ZS, Kawelblum M, Cheung YY, et al. Osgood-Schlatter lesion: fracture or tendinitis? Scintigraphic, CT, and MR imaging features. Radiology 1992;185:853-8.

16 Bloom RA, Gomori J, Milgrom C. Ossicles anterior to the proximal tibia. Clin Imaging 1993:17:137-41.

17 Krause BL, Williams JP, Catterall A. Natural history of Osgood-Schlatter disease. J Pediatr Orthop 1990;10:65-8.

18 Ducher G, Cook J, Spurrier D, et al. Ultrasound imaging of the patellar tendon attachment to the tibia during puberty: a 12-month follow-up in tennis players. Scand J Med Sci Sports 2010;20:e35-40.

19 Grechenig W, Mayr JM, Peicha G, et al. Sonoanatomy of the Achilles tendon insertion in children. J Clin Ultrasound 2004;32:338-43.

20 Cook JL, Purdam CR. Is tendon pathology a continuum? A pathology model to explain the clinical presentation of load-induced tendinopathy. Br J Sports Med 2009;43:409-16

21 Bjur D, Alfredson $\mathrm{H}$, Forsgren S. The innervation pattern of the human Achilles tendon: studies of the normal and tendinosis tendon with markers for general and sensory innervation. Cell Tissue Res 2005:320:201-6.

22 Ljung BO, Alfredson H, Forsgren S. Neurokinin 1-receptors and sensory neuropeptides in tendon insertions at the medial and lateral epicondyles of the humerus. Studies on tennis elbow and medial epicondylalgia. J Orthop Res 2004:22:321-7.

23 Ljung BO, Forsgren S, Friden J. Sympathetic and sensory innervations are heterogeneously distributed in relation to the blood vessels at the extensor carp radialis brevis muscle origin of man. Cells Tissues Organs 1999;165:45-54

24 Jensen MP, Chen C, Brugger AM. Interpretation of visual analog scale ratings and change scores: a reanalysis of two clinical trials of postoperative pain. J Pain 2003:4:407-14.

25 Campbell WI, Patterson CC. Quantifying meaningful changes in pain. Anaesthesia 1998;53:121-5

26 Gao J, Messner K, Ralphs JR, et al. An immunohistochemical study of enthesis development in the medial collateral ligament of the rat knee joint. Anat Embryol (Berl) 1996:194:399-406.

27 Ogden JA, Southwick WO. Osgood-Schlatter's disease and tibial tuberosity development. Clin Orthop Relat Res 1976;(116):180-9.

28 Benjamin M, Rufai A, Ralphs JR. The mechanism of formation of bony spurs (enthesophytes) in the achilles tendon. Arthritis Rheum 2000;43:576-83.

29 Gerber HP, Ferrara N. Angiogenesis and bone growth. Trends Cardiovasc Med 2000;10:223-8

30 Garcia-Ramirez M, Toran N, Andaluz P, et al. Vascular endothelial growth factor is expressed in human fetal growth cartilage. J Bone Miner Res 2000;15:534-40.

31 Gerber HP, Vu TH, Ryan AM, et al. VEGF couples hypertrophic cartilage remodeling, ossification and angiogenesis during endochondral bone formation. Nat Med 1999:5:623-8.

32 Colnot $\mathrm{Cl}$, Helms JA. A molecular analysis of matrix remodeling and angiogenesis during long bone development. Mech Dev 2001;100:245-50.

33 Benjamin M, Ralphs JR. Fibrocartilage in tendons and ligaments —an adaptation to compressive load. J Anat 1998;193 (Pt 4):481-94.

34 McGonagle $\mathrm{D}$, Benjamin M, Marzo-Ortega $\mathrm{H}$, et al. Advances in the understanding of entheseal inflammation. Curr Rheumatol Rep 2002;4:500-6.

35 Czyrny Z. Osgood-Schlatter disease in ultrasound diagnostics-a pictorial essay. Med Ultrason 2010;12:323-35.

36 Ogden JA, Tross RB, Murphy MJ. Fractures of the tibial tuberosity in adolescents. J Bone Joint Surg Am 1980;62:205-15.

37 Flowers MJ, Bhadreshwar DR. Tibial tuberosity excision for symptomatic Osgood-Schlatter disease. J Pediatr Orthop 199515:292-7.

38 Mital MA, Matza RA, Cohen J. The so-called unresolved Osgood-Schlatter lesion: a concept based on fifteen surgically treated lesions. J Bone Joint Surg Am 1980;62:732-9.

39 Hussain A, Hagroo GA. Osgood-Schlatters disease. Sports Exerclnj 1996:2:202-6. 